\title{
Development of the Oxyacetylene Welding Process for PEl/Glass Fiber Laminates
}

\author{
The optimization of welding parameters was performed using complete \\ factorial planning $2^{2}$, with time and distance of the flame as variables
}

BY V. S. OLIVEIRA, R. R. LUCAS, T. P. CARVALHO, L. F. MARQUES, J. F. REIS, A. B. R. M. ABRAHÃO, AND E. C. BOTELHO

\begin{abstract}
The technology for joining thermoplastics through welding offers numerous advantages over mechanical joining. Currently, the joining of composite parts with weight reduction and cost savings is being developed to improve aircraft performance. This paper proposes the use of oxygenacetylene as a process for bonding composite materials. Oxyacetylene welding is a simple and economical method that can be suitable for polymeric materials. The advantage of applying this technique is a more accessible process that is composed of a portable system with low cost. In evaluating the welding efficiency for composite materials, the lap shear strength (LSS) mechanical test stands out among the most referenced essays in the literature. This work aimed to study the development of oxyacetylene flame welding as well as the optimization of welding parameters for polyetherimide/glass fiber composite. The optimization was performed using complete factorial planning $2^{2}$ as a tool, and the variables studied were time and distance of the flame. With the optimized condition set as the response variable with the highest lap shear value, the joints obtained were measured for their quality by means of end-notched flexure mechanical testing, thermal analysis, and fracture analysis after LSS testing using optical and electronic microscopy.
\end{abstract}

\section{KEYWORDS}

- Composites • Factorial Planning • Hybrid Welding

- Oxyacetylene • Manufacturing • Aluminum

\section{Introduction}

Thermoplastic composites reinforced with continuous fibers have been studied in a wide variety of applications, including commercial with low cost involved and engineering, and found to have high benefits (Refs. 1-3). In comparison with aerospace thermosets, the main advantages of fiberreinforced thermoplastic composites, such as polyphenylene sulfide (PPS) and polyetherimide (PEI), are in the fact that these materials can be stored at room temperature, allowing for faster cycle times in the manufacture of pressed parts, and have higher efficiency in the welding assembly (Refs. 4, 5). In addition, thermoplastic composites offer many interesting features, such as high fracture toughness, high damage tolerance, reprocessing, and lower recycling and storage costs (Refs. 6, 7).

Among the most used thermoplastic polymers as a matrix for composites, PEI stands out. Polyetherimides are high-performance amorphous thermoplastics with excellent mechanical, thermal, and chemical properties, even at high temperatures (Refs. 8, 9). Welding composite materials has additional significant advantages over traditional joining methods (adhesives and mechanical fixing), given reduced assembly time without increasing weight. Bonding using adhesives is time-consuming, and volatile organic solvents involve problems that include a possible risk to the health of operators. In addition, welding is able to overcome the limitations related to the adhesive and avoid the weight gain of a structure assembled by mechanical fixation (Refs. 10, 11).

Different welding processes have been developed for several applications and procedures. The main processes for joining thermoplastic composite materials are ultrasonic welding (USW), resistance welding (RW), and induction welding (IW) (Refs. 10, 12, 14).

However, despite the great advantages and ample information described in the literature for these main welding processes for composites, they have some disadvantages. Electrical RW and IW require relatively long welding cycles (Refs. 17, 19), and IW uses expensive equipment (Ref. 16). In USW, there is difficulty in automating the process (Ref. 16), and it has a limited welding area (Ref. 12).

Welding bonding techniques can be classified according to the technology used to generate heating (Refs. 20, 21). There are several processes that are used for welding thermoplastics. Among these techniques, the hot gas process uses an electric heater to heat the gas and direct it to the welding region. Also, in search of new welding methods, the oxyfuel gas welding process has been viable, because in addition to its similarity to conventional methods of hot gas welding, this method is inexpensive and more versatile, as it does not require electricity (Refs. 5, 14, 22).

During the process, voids may form in welded compos- 


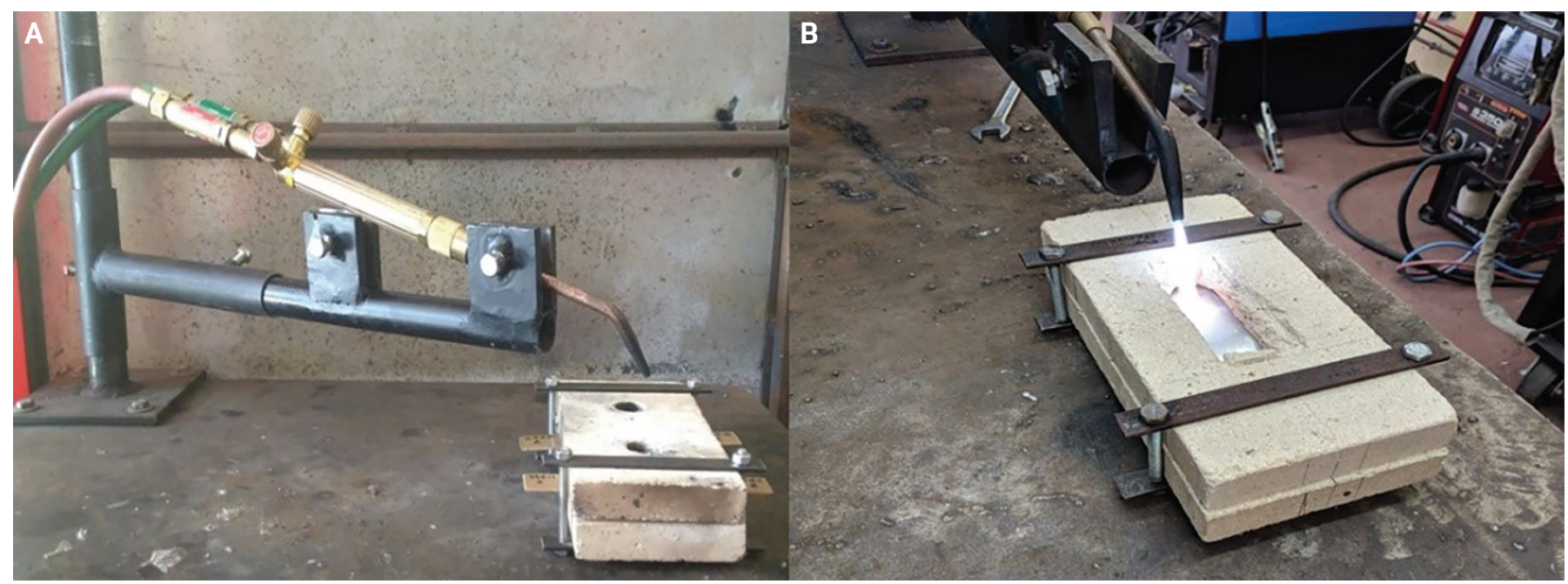

Fig. 1-A - The welding system developed for joining thermoplastic composites for LSS samples; B - the application of welding on the device to obtain ENF samples.

ites, leading to weld line failures. This may be related to the presence of volatile polymer matrix or weld waste gases, resulting in delamination of the composite (Refs. 23, 25).

Temperature and pressure control during the welding process are of great importance to avoid the formation of voids in the welded composites (Refs. 26, 27). However, investigating the presence of voids in the welded material is a good indicator of welding quality by assessing whether the adhesion process was effective.

This article presents the development and optimization of parameters for welding glass fiber (GF)/PEI composites via oxyacetylene flame (oxyacetylene welding process, also known as oxyfuel gas welding). The welding parameters were evaluated by experimental planning. The coupons submitted from the oxyacetylene welding process were characterized by LSS and end-notched flexure (ENF) tests, to evaluate the failure mode II. The morphology of the fracture resulting from the mechanical tests was evaluated by optical and scanning electron microscopy.

\section{Materials and Methods}

\section{Laminates}

The laminate used in this work was processed and supplied by Toray Advanced Composites. The GF/PEI composite fabric laminate was prepared with glass fiber $8 \mathrm{HS}$ style, in the configuration of $(0 / 90)_{5 s}$, containing approximately $50 \%$ in volume of reinforcement, providing a final thickness between 2.0 and $3.5 \mathrm{~mm}$.

\section{Oxyacetylene Welding Process}

The process selected for this study was welding by oxyacetylene gas, due to its versatility and easy handling. It also does not require an electrical source and can be welded autogenously. This process is known to have three types of flame: fuel, neutral, and oxidant, each of which can be adjusted by combining gas flow or noting the appearance of the gas. It is noteworthy that some literature defends the definition of these flames by a certain flow value and others by appearance of the flame (Ref. 20). In this work, the flame type was defined by the visual appearance of the flame. The first sample was welded with the fuel flame, which is acquired with more acetylene than oxygen, and the appearance is an elongated orange profile. However, in this case, immediately after welding, it was observed that the flame left a layer of soot that interfered with the temperature measurement. Thus, the type of flame used in this welding was the oxidant. With a flow rate of $0.5 \mathrm{~m}^{3} / \mathrm{s}$ of acetylene and $1.0 \mathrm{~m}^{3} / \mathrm{s}$ of oxygen, it was characterized by excess oxygen in relation to acetylene and the higher temperature of the flames. With the optimization of gas flows, the oxidizing flame acquired a blue profile with a characteristic noise. At the end of welding with this flame, the absence of soot was noted, and as oxygen increased the flame temperature, the welding time decreased.

\section{Development of the Welding Device}

An important point for welding in advanced polymer matrix composites is the welding temperature range (welding window). The PEI has a degradation temperature start of approximately $460^{\circ} \mathrm{C}$ (Ref. 26). The glass transition temperature (Tg) is approximately $217^{\circ} \mathrm{C}$ (Ref. 27), and for this, the temperature was measured during and after welding with the use of a Lasergrip GM400 infrared thermometer with a capacity of $-50^{\circ}$ to $400^{\circ} \mathrm{C}$, with the temperature varying between $230^{\circ}$ and $250^{\circ} \mathrm{C}$. For welding to occur, this material must be subjected to temperatures above its $\mathrm{Tg}$; however, it must not reach its temperature of thermal degradation during the process. Between these ranges, the polymer softens and solidifies, causing a union and thus forming a joint. Additionally, to guarantee the quality and efficiency of composite material joints obtained by welding, it is necessary to ensure the heating does not harm the polymeric matrix, as this would be compromising the mechanical property of the material. In this work, for the execution of welding using the oxyacetylene process, a device was first built with refrac- 


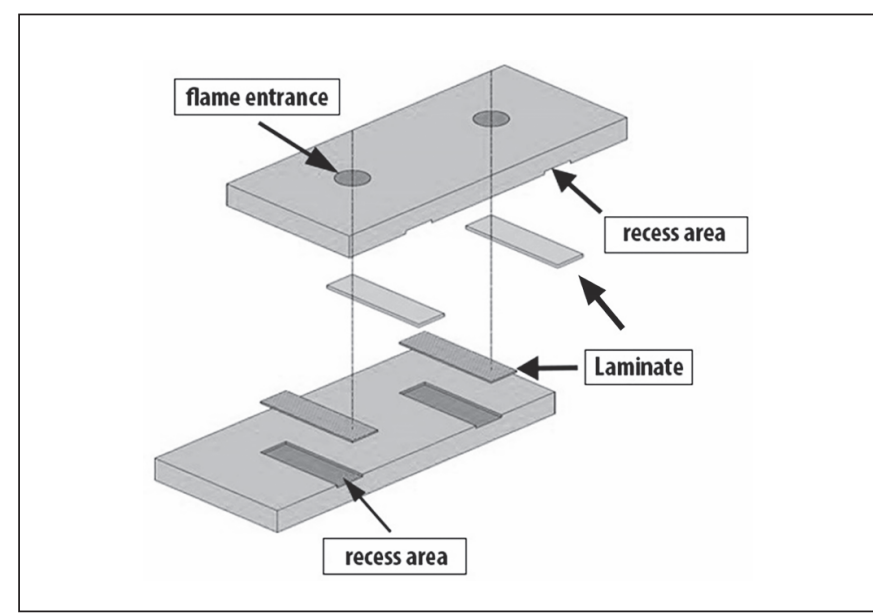

Fig. 2 - The welding system diagram.

tory brick to protect the region of the composite, in addition to preserving the heat of the flame in the welding region through a hole in the dimensions of the regions to be welded.

In addition, studying the process with oxyacetylene, it was possible to define the variables that would be used in welding. The authors of this paper analyzed whether the overlapping sample would be attached to the device, how to choose the type of flame, and how the sample would be protected.

It was necessary to develop a protection device for the sample, as the flame in direct contact with the sample degrades the fibers and polymeric matrix, compromising the thermal and mechanical properties of the welded composite. For this purpose, thermoplastic composites were joined via thermal conduction, using aluminum Alloy 2024 T3. Due to its high capacity to conduct heat, the welding flame was applied directly to Alloy 2024 T3, heating it at temperatures that approach the Tg of the PEI composite, where the material softens and, consequently, the joining of these two materials occurs. As a result of the process, Alloy 2024 T3 protects the composite material from being directly exposed to the welding flame. Thus, the form of overlap welding was adopted in the project.

For the thermal conduction of heat for the composite and protection of the composite by avoiding direct exposure to the flame, Alloy 2024-T3 plates in the dimensions of $45 \times 45$ $\mathrm{mm}$ were used for LSS samples and $25 \times 100 \mathrm{~mm}$ for ENF samples. They were attached to the refractory brick between the hole and the composite material. Thus, the flame came into direct contact with the protective aluminum, and it transmitted heat by thermal conduction to the composite.

With the sample duly protected, another variable to be evaluated in the process was the distance from the nozzle of the torch to the sample. Thus, for the control to be made, the blowtorch was disposed in a steel arm available on the weld bench, which facilitated establishing the distance values from the flame to the samples. Figures 1 and 2 present the system used to perform the welding of the composite. To prevent the polymer composite sample from adhering to the aluminum in the welding process, a demolding agent (Polidesmo 55) was used between these two components.
Table 1- Actual and Coded Levels for the Time and Flame Distance Variables Evaluated According to Experimental Design for GF/PEI Laminate Welded by Oxyacetylene Welding

\begin{tabular}{ccccccc} 
Variables & & \multicolumn{5}{c}{ Levels } \\
Real & Coded & $-\alpha$ & -1 & 0 & +1 & $+\alpha$ \\
\hline Time $(\mathrm{s})$ & $\mathrm{X}_{1}$ & 35.86 & 40 & 50 & 60 & 64.14 \\
Flame distance (mm) & $\mathrm{X}_{2}$ & 35.86 & 40 & 50 & 60 & 64.14 \\
\hline
\end{tabular}

\section{Experimental Planning}

To determine the more appropriate parameters for welding by the oxyacetylene process, a central composite design (CCD) experimental design was used considering the $\mathrm{k}$ factor ( $\mathrm{k}=2$ = welding time and flame distance), which is a matrix formed by two distinct groups of experimental elements: a complete factorial $2^{2}$ design with a certain number of central points (in this work, five replicates were considered at the central point). Additionally, the matrix presents a group of extra levels called axial points in a CCD, this being equal to twice the number of factors involved in the experiment $\left(2^{2}=4\right)$, considering the LSS test as the variable response of this analysis.

\section{LSS Test}

For the LSS test, a Shimadzu AG-X universal testing machine was used. This test was performed with a $50-\mathrm{kN}$ load cell at $1.5 \mathrm{~mm} / \mathrm{min}$, according to ASTM D5868, Standard Test Method for Lap Shear Adhesion for Fiber Reinforced Plastic (FRP) Bonding - Fig. 3.

\section{ENF Test}

The ENF test is a method used to measure interlaminar fracture toughness in mode II (shear loading) in composite materials. This is essentially unstable and produces only the initiation value of mode II of tenacity to interlaminar fracture. For the ENF test, a total of ten samples were tested at a speed of $1 \mathrm{~mm} / \mathrm{min}$, and the propagation of the interlaminar crack was observed in all samples, according to ASTM D7905/D7905M, Standard Test Method for Determination of the Mode II Interlaminar Fracture Toughness of Unidirectional Fiber-Reinforced Polymer Matrix Composites. Equation 1 was used to calculate the energy rate of interlaminar fracture toughness in mode II: $G_{I I} c$.

$$
G_{I I} c \frac{9 a^{2} P \delta}{2 b\left(2 L^{3}+3 a^{3}\right)}
$$

Where $a=$ crack length $(\mathrm{m}) ; P=$ force $(\mathrm{N}) ; \delta=$ displacement (m); $b=$ width of the specimen (m); and $L=$ distance between supports (m). During the execution of the test, each sample was filmed to measure the propagation of the interlaminar crack in the material until the end of the test. Crack propagation was monitored every $1 \mathrm{~min}$, illustrated in Figs. 4 and 5 and using ImageJ software to measure the crack length. 


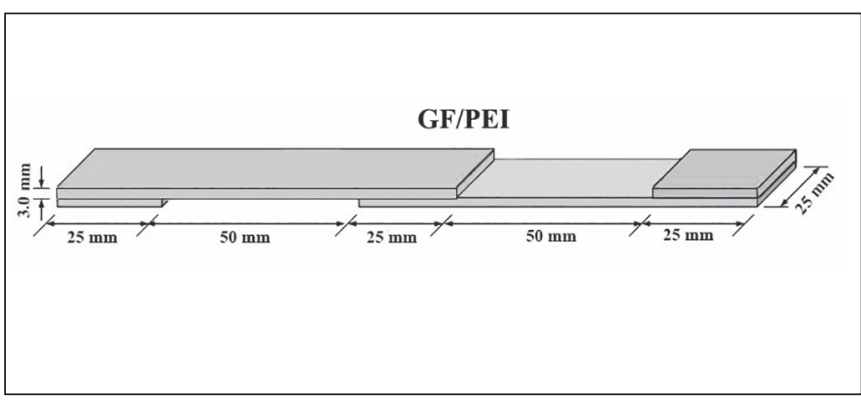

Fig. 3-Geometry for the LSS test.

\begin{tabular}{cccc}
\hline \multicolumn{4}{l}{ Table 2 - Experimental Matrices and LSS Results } \\
Tests & Time (s) & Distance (mm) & LSS (MPa) \\
\hline 1 & 40 & 40 & 8.00 \\
2 & 60 & 40 & 12.30 \\
3 & 40 & 60 & 4.50 \\
4 & 60 & 60 & 11.30 \\
5 & 35.86 & 50 & 4.40 \\
6 & 64.14 & 50 & 11.10 \\
7 & 50 & 35.86 & 11.30 \\
8 & 50 & 64.14 & 6.00 \\
9 & 50 & 50 & 12.50 \\
10 & 50 & 50 & 12.10 \\
11 & 50 & 50 & 11.00 \\
12 & 50 & 50 & 10.50 \\
13 & 50 & 50 & 12.40 \\
\hline
\end{tabular}

\section{Microscopy Analyses}

To characterize the composite and evaluate the efficiency of the oxyacetylene welding process, optical microscopy analyses were performed on the laminate after mechanical tests. After analyzing the welded and fractured regions, a sample of the more appropriate welding condition was selected to be analyzed by scanning electron microscopy (SEM). The samples were metallized by metal spraying using gold plasma to make their analysis surface conductive. The process was utilized on a Quorum Q150R ES.

\section{Thermal Analyses}

The thermogravimetry test (TGA) was carried out to evaluate variations in the degradation temperature of the welded material. A condition sample was evaluated, with the analyses being carried out in a controlled nitrogen atmosphere (100 $\mathrm{mL} / \mathrm{min}$ ) with an initial temperature of $30^{\circ} \mathrm{C}$ and a final temperature of $1000^{\circ} \mathrm{C}$ at a heating rate of $10^{\circ} \mathrm{C} / \mathrm{min}$, with samples of a mass of approximately $10 \mathrm{mg}$. In addition, dynamic mechanical analysis (DMA) was carried out with the aim of evaluating whether the glass Tg of the welded GF/PEI composite was influenced by the process. A sample was evaluated for each condition in the dimensions of $55 \mathrm{~mm}$ long by $10 \mathrm{~mm}$ wide and $3 \mathrm{~mm}$ high. The test was carried out in a controlled atmosphere of nitrogen at $10 \mathrm{lb} / \mathrm{in}^{2}{ }^{2}$ and initial temperature of $30^{\circ} \mathrm{C}$ and final temperature of $250^{\circ} \mathrm{C}$ with a heating rate of $3^{\circ} \mathrm{C} / \mathrm{min}$, frequency of $1 \mathrm{~Hz}$, amplitude of $10 \mu \mathrm{m}$, and dual cantilever measurement mode. The equipment used was an SII Nanotechnology TG/DTA 6200.

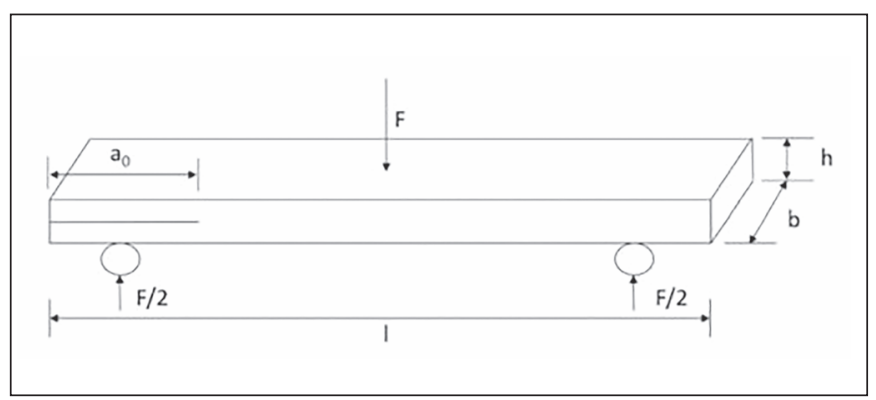

Fig. 4 - Specimen geometry for the ENF test.

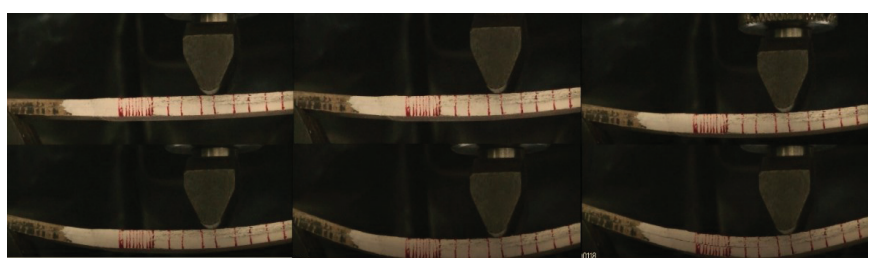

Fig. 5 - Performing the ENF test with a displacement of 1 $\mathrm{mm} / \mathrm{min}$ between each frame.

\section{Results and Discussion}

\section{Experimental Planning}

As the experimental design called CCD was presented for $\mathrm{k}=2$ factors, it is a matrix formed by three distinct groups of experimental elements: a complete factorial $2^{2}$ and a design with a certain number of central points (in this work, five replicates were evaluated at the central point), which additionally presents a group of extra levels called axial points.

The values obtained from the LSS tests in Table 2 are in the range of 4.36-12.54 MPa, highlighting the maximum value from Test 9. With the construction of the model, its significance was verified through the analysis of variance (ANOVA), and this test evaluates if the model is statistically significant.

The result obtained of $12.5 \mathrm{MPa}$ in the study is in the range of values when compared to other welding processes already consolidated in the literature, such as the process by electrical resistance in composites reinforced with glass fibers. A range of values from 8.83 to $33 \mathrm{MPa}$ are found for welding this type of material (Refs. 14, 15, 25).

Associated with this coefficient is the adjusted R2, which takes into account the fact that $\mathrm{R}^{2}$ tends to overestimate the current amount of variation accounted for by the population (Ref. 16). The ANOVA results for studies of the effects of time and temperature variables for welding of GF/PEI composites are presented in Table 2.

From these results, it can be observed that the analyzed variables (time and distance) were significant when applied independently. The P Test (Table 3) indicated statistical significance at the $99 \%$ confidence level, and no lack of adjustment was found for any of the models evaluated (90\% confidence level). It was also verified, from the value of $\mathrm{R}^{2}$, that all the adjusted equations were able to explain more than $94 \%$ of the variability of the experimental values. Thus, it was considered that the obtained statistical models were adequate to describe the welding process of the laminates. 


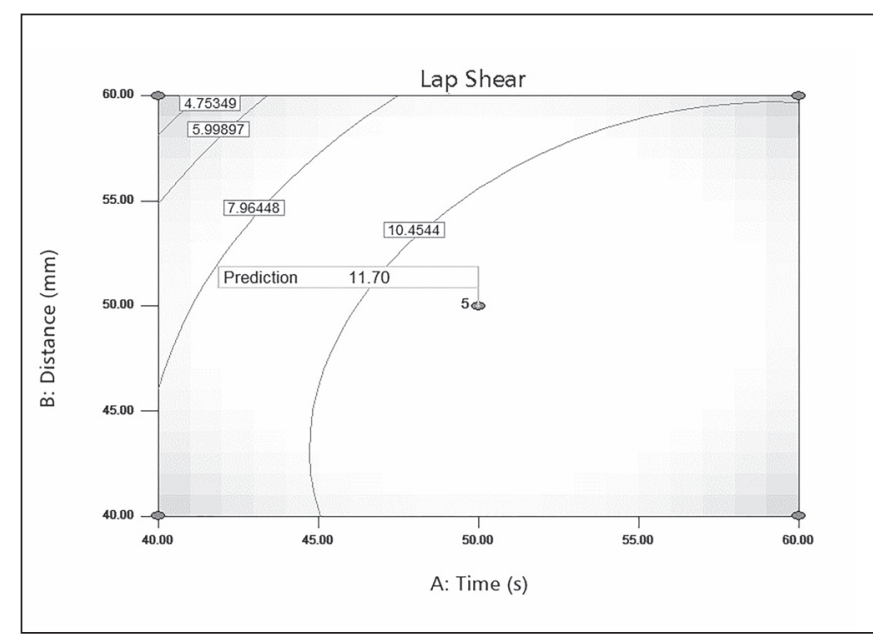

Fig. 6 - Level curves for GF/PEI composite.

\section{Welding Process Optimization}

From the results of the ANOVA (Table 3), it was possible to compose the statistical models including the coefficients corresponding to the significant effects for the welding process of the laminates. The model obtained is presented by Equation 2 .

$$
\begin{gathered}
\text { LSS }(\mathrm{MPa})=-55 \times 70+1.72 \times \mathrm{X}_{1}+0.87 \times \mathrm{X}_{2}-0.02 \\
\times \mathrm{X}_{12}-0.01 \times \mathrm{X}_{22}
\end{gathered}
$$

Where $\mathrm{X}_{1}=$ welding time in seconds, and $\mathrm{X}_{2}=$ flame distance in millimeters. Generally, to estimate the coefficients defined by the model of Equation 1, the ordinary least squares (OLS) method is typically used. Thus, an approximate function is built relating the responses of interest with the process variables. Using the Design-Expert program, for this work we proceeded to search for the maximum LSS values within the values for the studied variables. From the optimized conditions, response surface graphs were built, using the same program, referring to the variable values seeking the highest values predicted by the LSS test model. Response surfaces with the optimization regions are shown in Figs. 6 and 7. Statistically analyzing the level curves obtained by welding the GF/PEI composite (Figs. 6,7 ) with the parameters predicted by the program of $50 \mathrm{~s}$ and $50 \mathrm{~mm}$ distance from the flame, it was observed that the LSS value was $11.83 \mathrm{MPa}$, when the predicted value was $11.70 \mathrm{MPa}$, showing the optimization is very close to ideal. This demonstrates reliability in the welding process developed for this material.

\section{Thermal Analysis}

Figure 8 illustrates the results obtained from the TGA (A) and the DMA (B) of the GF/PEI composite welded by the oxyacetylene welding process. From the TGA results, it can be seen that the degradation temperatures, characterized by the beginning of the derivative thermogravimetry peak or by the inflection in the TGA curve, depending on the temperature, of the welded materials present the same degradation temperature range, being approximately $450^{\circ} \mathrm{C}$. Thus, welding did not change the temperature of thermal degrada-

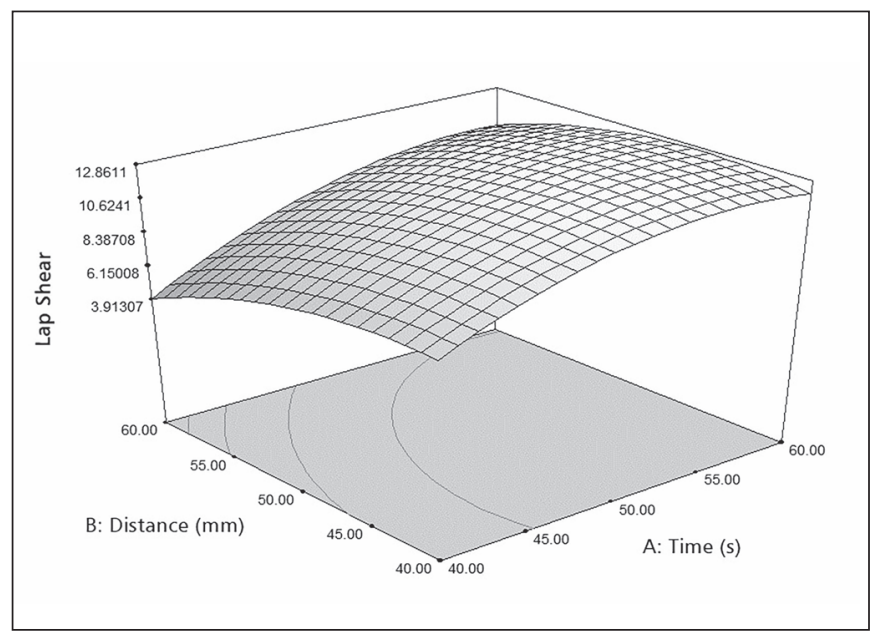

Fig. 7-Response surface.

tion of the thermoplastic matrix in the composite. Consequently, it can be said that the welding process carried out did not damage the polymer matrix. In addition, a Tg value was obtained from the DMA of approximately $200^{\circ} \mathrm{C}$, a value close to that found in the literature for PEI, meaning welding did not influence this thermal aspect of the thermoplastic composite.

\section{Welded Joint Characterization under Optimized Conditions}

Figure 9 illustrates the microscopy performed on the composites after the welding process and the LSS test, where the interaction between the polymeric matrices and the quality of the fibers in the welding of the material under the optimized conditions was investigated.

The fibers in both processes present a good preservation indicating a good degree of wettability of the polymeric matrix without the degradation of the glass fibers. The greater the intensity of the shiny aspect in the material, the lower the values obtained for strength in the LSS and ENF tests. This fact is

Table 3 - Analysis of Variance (ANOVA) for the Quadratic Model of GF/PEI Composite Welding in Experiments Conducted According to Statistical Planning

\begin{tabular}{cccc} 
Factor & Quadratic Sum & $\mathrm{F}$ & $\mathrm{P}$ \\
\hline Model & 103.18 & 23.03 & $0.0003^{*}$ \\
$\mathrm{~A}$ & 53.81 & 60.04 & $0.0001^{*}$ \\
$\mathrm{~B}$ & 17.60 & 19.64 & $0.0030^{*}$ \\
$\mathrm{~A}^{2}$ & 21.72 & 24.24 & $0.0017^{*}$ \\
$\mathrm{~B} 2$ & 12.25 & 13.67 & $0.0077^{*}$ \\
AB & 1.54 & 1.72 & 0.2316 \\
Lack of & 2.90 & 1.14 & 0.4331 \\
adjustment & & & - \\
Residual & 6.27 & - & - \\
error & & & - \\
Pure error & 3.38 & - & - \\
R $^{2}$ & 0.94 & - & \\
\hline
\end{tabular}

${ }^{*} \mathrm{P}$ : Significant values for $\mathrm{P}<0.05$, A: time; B: flame distance. 


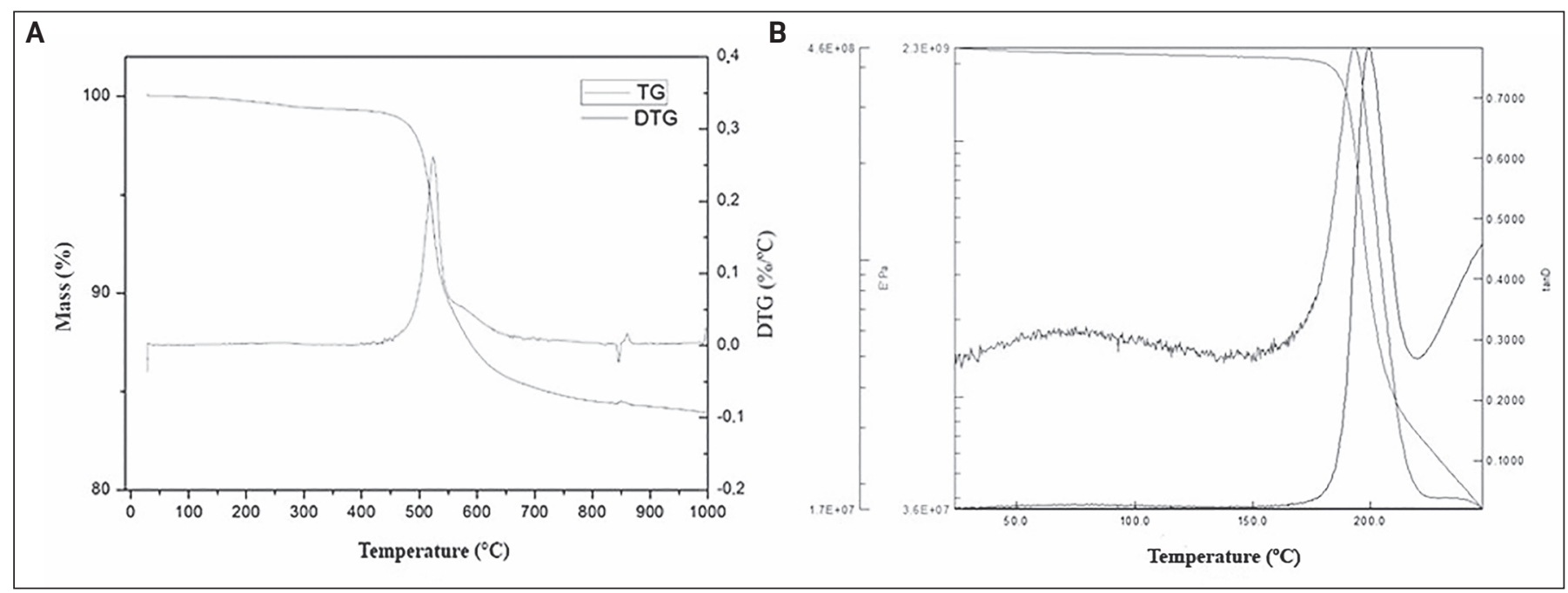

Fig. 8-A - TGA of the GF/PEI composite welded by the oxyacetylene process; B - analysis of composite DMA GF/PEI welded by the oxyacetylene process.

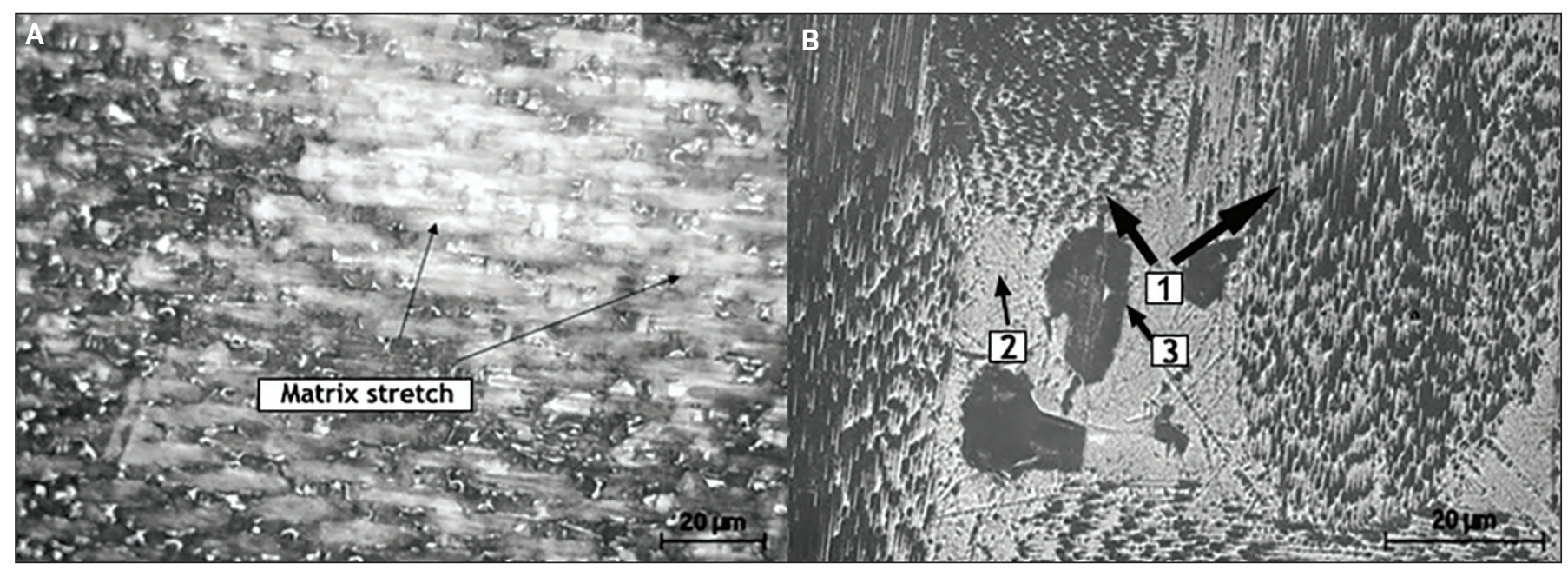

Fig. 9-A - Macroscopy of samples welded by oxyacetylene. Magnification of 0.65x; B - optical microscopy performed on samples welded by oxyacetylene. Magnification of $5 x$.

Table 4- Mean Values Obtained for Interlaminar Fracture Toughness $\left(\mathbf{G}_{\|} \mathbf{C}\right)$

\begin{tabular}{cc} 
Welding & $\left(\mathrm{J} / \mathrm{m}^{2}\right)$ \\
\hline This study & 2635.8 \\
Literature & $3206-4339$ \\
\hline
\end{tabular}

indicative of a weaker interaction between the interfaces of the polymeric matrix (between one composite part and the other) forming a less resistant interaction surface. Additionally, the matrix stretches are a sign of mechanical effort for their rupture, indicating a good adhesion between the polymeric matrices. In Fig. $9 \mathrm{~B}$, the arrows indicate the fundamental elements of the analysis where 1 is the fibers in different directions, 2 is the polymeric matrix, and 3 is marks caused by the stretching of the polymeric matrix during the mechanical test. It is possible to observe the absence of concentrated voids in central regions of the images. The absence of concentrated voids in certain regions points to a uniform distribution of heat during welding as a function of the temperature and pressure of the welding process (Ref. 28).

\section{Analysis of the Mechanical Test by ENF}

Table 4 shows the values of the interlaminar fracture toughness $\left(G_{I I} c\right)$ obtained from the test and the values obtained from the literature (Refs. 30, 31) regarding the ENF test in GF/PEI composite.

As observed in Table 4, the oxyacetylene welded composites showed values close to those found in the literature for GF/PEI composites welded by electrical resistance (the method to which the welding was carried out and the consequent ENF test of the material under study).

These data indicate that the welding process showed satisfactory joints with good interaction between the matrices of each welded interface. The value obtained from $G_{I I} c$ can be directly related to the effect of the thermal exposure of the material during processing. As the heat from the flame was transmitted from the protective aluminum to the composite so that the interfaces to be welded softened, the heat traveled the entire volume of the material until it reached the 


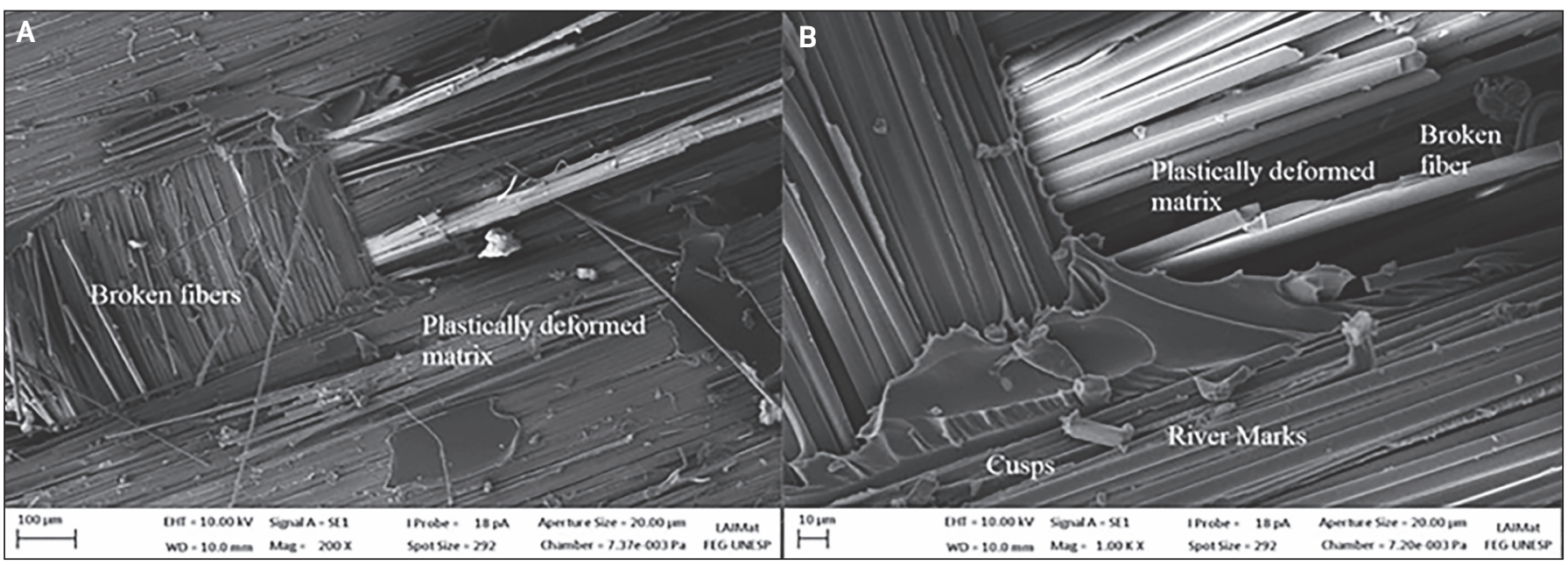

Fig. 10 - SEM analysis on fractured ENF samples of composite GF/PEI. A - Magnification 200x; B - magnification of 1000x.

interfaces in contact under pressure. This process resulted in a thermal expansion of both the matrix and the fibers and, because they are dissimilar materials, they presented different thermal expansion coefficients. This may result in the appearance of microdefect principles such as pores and microcracks, favoring the appearance and propagation of interlaminate cracks during the mechanical request of the test. Figure 10 shows results from scanning electron microscopy of samples welded by oxyacetylene.

From the obtained images it is possible to observe that the fracture surfaces of both figures are rich in fractographic aspects, with the presence of flaws from the thermoplastic matrix. The figures show cusps from the shear between the fiber/matrix regions. Also observed are regions of detached and broken fibers along with river marks in regions with a higher volume of the polymeric matrix. These factors are indicators of intralaminar failures. The river marks were formed by several uneven crack planes directed to a single plane while the fault propagated in the material. The river marks converged in a direction where the crack had grown. It is also possible to notice fiber print marks on the polymeric matrix and plastic deformations of the matrix, resulting from the viscoelastic characteristic of the polymeric matrix. In addition, Fig. 10 shows a good consolidation between the welded joints through the broken fibers with the presence of a thin covering of the polymer matrix. However, there was a significant reduction in the polymer matrix covering the broken glass fiber wires and the number of strands that were detached with the absence of a polymeric matrix, indicating less interaction between the welded matrices (Ref. 31). This fact indicates a slightly weaker interfacial adhesion of the welding process when compared to the other process, corroborating with the data obtained through mechanical tests.

\section{Conclusion}

Based on the results obtained in this work, it is possible to establish a better statistical model to evaluate the most suitable parameters for the welding of GF/PEI composite by the oxyacetylene process. With welding parameters of $50 \mathrm{~s}$ at a distance of $50 \mathrm{~mm}$, a LSS value of $12.50 \mathrm{MPa}$ was ac- quired, which is an interesting value in relation to other processes with the same material. In addition, the adaptation of the refractory device provided suitable welding for the composite without degradation of the sample, as proven by the microscopic and visual analysis of the laminate. Fractography showed failure mechanisms in oxyacetylene welding, obtaining results rich in details in regions with higher density of the polymeric matrix, such as cusps, river marks indicating the direction of failure propagation, plastic deformation of the matrix, glass fiber detachment and breakage, and printing marks of metal mesh and glass fibers in the polymer matrix. These fractographic aspects are indicators of intralaminar failure, characterizing a good interaction and molecular diffusion of the polymer between the interfaces in contact.

\section{Acknowledgments}

This study was financed by the FAPESP (São Paulo Research Foundation) under project 2017/16970-0 and CNPq under project 303224/2016-9.

\section{References}

1. Botelho, E. C., Scherbakoff, N., Rezende, M. C., Kawamoto, A. M., and Sciamareli, J. 2001. Synthesis of polyamide $6 / 6$ by interfacial polycondensation with the simultaneous impregnation of carbon fibers. Macromolecules 34: 3367-3375. DOI: 10.1021/ ma000902k

2. Khan, M. A., Syed, A. K., Ijaz, H., and Shah, R. M. B. R. 2018. Experimental and numerical analysis of flexural and impact behaviour of glass/pp sandwich panel for automotive structural applications. Advanced Composite Materials 27: 367-386. DOI: 10.1080/ 09243046.2017.1396199

3. Okabe, T., Motani, T., Nishikawa, M., and Hashimoto, M. 2012. Numerical simulation of microscopic damage and strength of fiber-reinforced plastic composites. Advanced Composite Materials 21: 147-163. DOI: 10.1080/09243046.2012.688495

4. Fischer, F. J. C., Beyrle, M., Thellmann, A. H., Endrass, M., 
Stefani, T., Gerngross, T., and Kupke, M. 2017. Corrugated composites: Production-integrated quality assurance in carbon fiber reinforced thermoplastic sine wave beam production. Advanced Manufacturing: Polymer and Composites Science 3: 10-20. DOI: 10.1080/ 20550340.2017.1283100

5. Tafreshi, O. A., Hoa, S. V., Shadmehri, F., Minh, D., and Rosca, D. 2019. Heat transfer analysis of automated fiber placement of thermoplastic composites using a hot gas torch. Advanced Manufacturing: Polymer and Composites Science 5: 206-223. DOI: 10.1080/ 20550340.2019.1686820

6. Zhang, X., Lu, C., and Liang, M. 2011. Preparation of thermoplastic vulcanizates based on waste crosslinked polyethylene and ground tire rubber through dynamic vulcanization. Journal of Applied Polymer Science 122(3): 2110-2120. DOI: 10.1002/app.34293

7. Zammar, I., Huq, M. S., Mantegh, I., Yousefpour, A., and Ahamadi, M. 2017. A three-dimensional transient model for heat transfer in thermoplastic composites during continuous resistance welding. Advanced Manufacturing: Polymer and Composites Science 3(1): 32-41. DOI: 10.1080/20550340.2017.1311094

8. Ramgobin, A., Fontaine, G., and Bourbigot, S. 2019. Thermal degradation and fire behavior of high performance polymers. Polymer Reviews 59(1): 55-123. DOI: 10.1080/15583724.2018. 1546736

9. Cacciotti, I., Rinaldi, M., Fabbrizi, J., and Nanni, F. 2019. Innovative polyetherimide and diatomite based composites: Influence of the diatomite kind and treatment. Journal of Materials Research and Technology 8(2): 1737-1745. DOI: 10.1016/j.jmrt.2018. 12.004

10. Lionetto, F., Pappadà, S., Buccoliero, G., and Maffezzoli, A. 2017. Finite element modeling of continuous induction welding of thermoplastic matrix composites. Materials and Design 120(15): 212-221. DOI: 10.1016/j.matdes.2017.02.024

11. Nagatsuka, K., Xiao, B., Wu, L., Natata, K., Saeki, S., Kitamoto, Y., and Iwamoto, Y. 2018. Dissimilar materials joining of metal/carbon fibre reinforced plastic by resistance spot welding. Welding International 32(7): 505-512. DOI: 10.1080/01431161. 2017.1346889

12. Villegas, I. F., Moser, L., Moser, A., Yousefpour, P., and Mitschang, H. E. N. 2013. Process and performance evaluation of ultrasonic, induction and resistance welding of advanced thermoplastic composites. Journal of Thermoplastic Composite Materials 26(8): 1007-1024. DOI: 10.1177/0892705712456031

13. Brassard, D., Dubé, M., and Tavares, J. R. 2019. Resistance welding of thermoplastic composites with a nanocomposite heating element. Composites Part B: Engineering 165(15): 779-784. DOI 10.1016/j.compositesb.2019.02.038

14. Dubé, M. et al. 2012.Metal mesh heating element size effect in resistance welding of thermoplastic composites. Journal of Composite Materials 46(8): 911-918.

15. Pannerselvam, K. et al. 2012. Study on resistance welding of glass fiber reinforced thermoplastic composites. Materials and Design 41: 453-459.

16. Yousefpour, A., Hojjati, M., and Immarigeon, J. P. 2004. Fusion bonding/welding of thermoplastic composites. Journal of Thermoplastic Composite Materials 17(4): 303-341. DOI: 10.1177/ 0892705704045187

17. Ageorges, C., and Ye, L. 2001. Resistance welding of metal/thermoplastic composite joints. Journal of Thermoplastic Composite Materials 14: 449-475. DOI: 10.1106/PN74-QXKH$7 \mathrm{XBE}-\mathrm{XKF} 5$

18. André, N. M., Goushegir, S. M., Santos, J. F., Canto, L. B., and Filho, S. T. 2016. Friction spot joining of aluminum Alloy 2024-T3 and carbon-fiber-reinforced poly(phenylene sulfide) laminate with additional PPS film interlayer: Microstructure, mechanical strength and failure mechanisms. Composites Part B: Engineering 94: 197-208. DOI: 10.1016/j.compositesb.2016.03.011

19. Mitschang, P., Velthuis, R., and Didi, M. 2013. Induction spot welding of metal/CFRPC hybrid joints. Advanced Engineering Materials 15(9): 804-813. DOI: 10.1002/adem.201200273

20. Palary, G., Shi, H., Levy, A., Le Corre, S., and Villegas, I. F. 2018. A study on amplitude transmission in ultrasonic welding of thermoplastic composites. Composites Part A: Applied Science and Manufacturing 113: 339-349. DOI: 10.1016/j.compositesa.2018. 07.033

21. Wang, K., Shriver, D., Li, Y., Banu, M., Hu, S. J., Xiao, G., Arinez, J., and Fan, H. T. 2017. Characterization of weld attributes in ultrasonic welding of short carbon fiber reinforced thermoplastic composites. Journal of Manufacturing Processes 29: 124-132. DOI: 10.1016/j.jmapro.2017.07.024

22. Messler, R. W. 2004. Joining of Materials and Structures: From Pragmatic Process to Enabling Technology. London, United Kingdom: Butterworth-Heinemann.

23. Chang, T., Zhan, L., Tan, W., and Li, S. 2017. Void content and interfacial properties of composite laminates under different autoclave cure pressure. Composite Interfaces 24(5): 529-540. DOI: 10.1080/09276440.2016.1237113

24. Shi, H., Villegas, I. F., Octeau, M. A., Bersee, H. E. N., and Yousefpour, A. 2015. Continuous resistance welding of thermoplastic composites: Modelling of heat generation and heat transfer. Composites Part A: Applied Science and Manufacturing 70: 16-26.

DOI: 10.1016/j.compositesa.2014.12.007

25. Warren, K. C., Anido, R. A. L., Freund, A. L., and Dagher, H. J. 2016. Resistance welding of glass fiber reinforced PET: Effect of weld pressure and heating element geometry. Journal of Reinforced Plastics and Composites 35(12): 974-985. DOI: 10.1177/ 0731684416633516

26. Costa, M. L., Rezende, M. C., and de Almeida, S. F. M. 2006. Effect of void content on the moisture absorption in polymeric composites. Polymer-Plastics Technology and Engineering 45(6): 691698. DOI: $10.1080 / 03602550600609549$

27. Shi, H., Villegas, I. F., and Bersee, H. E. N. 2017. Analysis of void formation in thermoplastic composites during resistance welding. Journal of Thermoplastic Composite Materials 30: 16541674. DOI: $10.1177 / 0892705716662514$

28. Reis, J. F., Abrahao, A. B. M., Costa, M. L., and Botelho, E. C 2018. Assessment of the interlaminar strength of resistancewelded PEI/carbon fibre composite. Welding International 32(2): 149-160. DOI: 10.1080/09507116.2017.1347329

29. Pozegic, T. R., King, S. G., Fotouhi, M., Stolojan, V., Silva, S. R. P., and Hamerton, I. 2019. Delivering interlaminar reinforcement in composites through electrospun nanofibres. Advanced Manufacturing: Polymer \& Composites Science 5(4): 155-171. DOI: 10.1080/20550340.2019.1665226

30. Yuan, Q., Mai, Y. W., Ye, L., and Hou, M. 2001. Resistance welding of carbon fiber reinforced polyetherimide composite. Journal of Thermoplastic Composite Materials 14(1): 2-19. DOI:

10.1106/XF4F-6NEH-9KGN-1Y4R

31. Zenasni, R., Bachir, A. S., Viña, I., Arguelles, A., and Viña, J. 2006. Effect of hygrothermomechanical aging on the interlaminar fracture behavior of woven fabric fiber/PEI composite materials. Journal of Thermoplastic Composite Materials 19(4): 385-398. DOI: 10.1177/0892705706059743

VITÓRIA SIMPLÍCIO OLIVEIRA (vitoriaoliveirafatec@gmail.com) and ANA BEATRIZ RAMOS MOREIRA ABRAHÃO are with Technology College - FATEC, Pindamonhangaba, Brazil. RAFAEL RESENDE LUCAS, TAYENNE PRADO CARVALHO, LUIS FELIPE MARQUES, JONAS FRANK REIS, and EDSON COCCHIERI BOTELHO are with the Department of Materials and Technology, School of Engineering, São Paulo State University UNESP, Guaratinguetá, Brazil. 